\title{
Long-term follow-up for patients with infantile hydrocephalus treated by choroid plexus coagulation
}

\author{
Atsushi Okano, MD, and Hideki Ogiwara, MD, PhD \\ Division of Neurosurgery, National Center for Child Health and Development, Tokyo, Japan
}

\begin{abstract}
OBJECTIVE Shunt surgery is the most common treatment for hydrocephalus, but it is associated with several long-term complications. Endoscopic choroid plexus coagulation (CPC) and endoscopic third ventriculostomy (ETV) are alternative surgeries that may avoid the need for shunt surgery. Although the short-term efficacy and safety of CPC have been reported in previous studies, long-term outcome, including not only avoiding shunt placement but also intellectual development, remains to be elucidated. The purpose of the present study was to investigate the long-term outcome of CPC.
\end{abstract}

METHODS The study population comprised patients who had infantile hydrocephalus treated by endoscopic CPC before the age of 24 months and who were followed until at least 5 years of age. Retrospective review was performed using the medical charts. The authors assessed educational status and the full-scale intelligence quotient (FSIQ) using the Wechsler Intelligence Scale for Children (WISC) IV as the means to evaluate the intellectual development.

RESULTS Fourteen patients with infantile hydrocephalus underwent CPC with or without ETV as a primary surgery. There were no intraoperative complications. In 7 patients (50\%), hydrocephalus was successfully controlled without shunt placement. Six patients (43\%) eventually required shunt placement. In one patient hydrocephalus was controlled by additional ETV. In the shunt-independent group, 4 patients went to age-appropriate school or achieved age-appropriate development according to intelligence quotient (IQ), 1 patient went to specialized school, and 2 patients had disabilities. In the shunt-dependent group, 4 patients went to an age-appropriate school or achieved age-appropriate development by IQ, 1 patient went to specialized school, and 1 patient had disabilities. The mean FSIQ score in 3 patients without shunts was 90 (range 89-91) and the mean FSIQ score in 4 patients with shunts was 80 (range 48-107). There was no significant difference in the rate of normal development between the shunt-independent group and the shuntdependent group ( $p=0.72$ ).

CONCLUSIONS The CPC with or without ETV can be a safe and effective treatment in children with infantile hydrocephalus. Long-term control of hydrocephalus and normal intellectual development can be achieved in successful cases. Further prospective studies should be required to elucidate appropriate indications.

https://thejns.org/doi/abs/10.3171/2018.6.PEDS1840

KEYWORDS choroid plexus coagulation; infantile hydrocephalus; long-term follow-up

$\mathrm{S}$ HUNT surgery is the most common treatment for children with infantile hydrocephalus. However, it can be associated with several long-term complications, such as shunt infection, shunt malfunction, and shunt dependency. Endoscopic choroid plexus coagulation (CPC) and endoscopic third ventriculostomy (ETV) are alternative surgeries that may avoid the need for shunt surgery. It is known that the success rate for ETV is rather low, especially in pediatric patients younger than 2 years of age..$^{4,712,14}$ More recently, Warf reported that ETV com- bined with CPC was more successful than ETV alone in infants $<1$ year of age in Sub-Saharan Africans, particularly for those with nonpostinfectious hydrocephalus and myelomeningocele (MMC). ${ }^{31}$ Stone and Warf reported that ETV combined with CPC was an effective treatment for infantile hydrocephalus in a North American population. ${ }^{29}$

The use of CPC alone was first reported by Scarff in $1952 .{ }^{26}$ The short-term efficacy and safety of CPC have been previously reported. ${ }^{18,19}$ Recently, Kulkarni et al.

ABBREVIATIONS CPC = choroid plexus coagulation; ETV = endoscopic third ventriculostomy; ETVSS = ETV success score; FSIQ = full-scale intelligence quotient; MMC = myelomeningocele; WISC $=$ Wechsler Intelligence Scale for Children.

SUBMITTED January 20, 2018. ACCEPTED June 6, 2018.

INCLUDE WHEN CITING Published online September 14, 2018; DOI: 10.3171/2018.6.PEDS1840. 
reported that Ugandan infants with postinfectious hydrocephalus showed no significant difference between patients treated with endoscopic ETV+CPC and patients treated with a ventriculoperitoneal shunting (VP shunt) with regard to cognitive outcomes at 12 months. ${ }^{16}$ However, a follow-up interval of 12 months is considered to be relatively short for assessing cognitive development, and long-term intellectual development of patients who have undergone CPC, with or without ETV, still remains unclear. The purpose of our study was to investigate the long-term outcome, including intellectual development, of patients who have undergone CPC.

\section{Methods}

\section{Patient Population}

Between 2002 and 2012, 187 patients with hydrocephalus under the age of 24 months were operated on at the $\mathrm{Na}$ tional Center for Child Health and Development in Tokyo (Fig. 1). Among them, 18 patients were treated primarily by endoscopic CPC with or without ETV, 27 patients by ETV, and 142 patients were treated primarily by shunt surgery. Four patients treated by CPC with or without ETV were lost to follow-up before reaching 5 years of age. Ul- timately we analyzed data obtained in 14 patients with infantile hydrocephalus who were followed until at least 5 years of age. The retrospective analysis included age, sex, presenting symptoms, surgical treatment, and clinical outcomes and was performed using the medical charts.

Diagnosis of hydrocephalus was made on the basis of clinical manifestation including increasing head circumference, tight fontanel, vomiting, and lethargy, as well as by imaging studies that revealed dilation of the ventricles. Preoperative MRI and CT scanning were performed in all patients to detect any obstructive etiology for hydrocephalus. Cine phase-contrast MRI and/or CT cisternography were used to detect any obstruction of CSF flow, including aqueductal stenosis or fourth ventricular outlet obstruction. We considered hydrocephalus to be communicating if there were no obstructions detected on the imaging studies. Our surgical indication for infantile hydrocephalus has been detailed in a previous report. ${ }^{20}$ Typically we selected ETV alone for obstructive hydrocephalus due to aqueductal stenosis or fourth ventricular outlet obstruction. We occasionally selected a combination of CPC and ETV for young infants with obstructive hydrocephalus because CSF absorption has not been fully developed in these patients. Ventriculoperitoneal shunt placement was usually

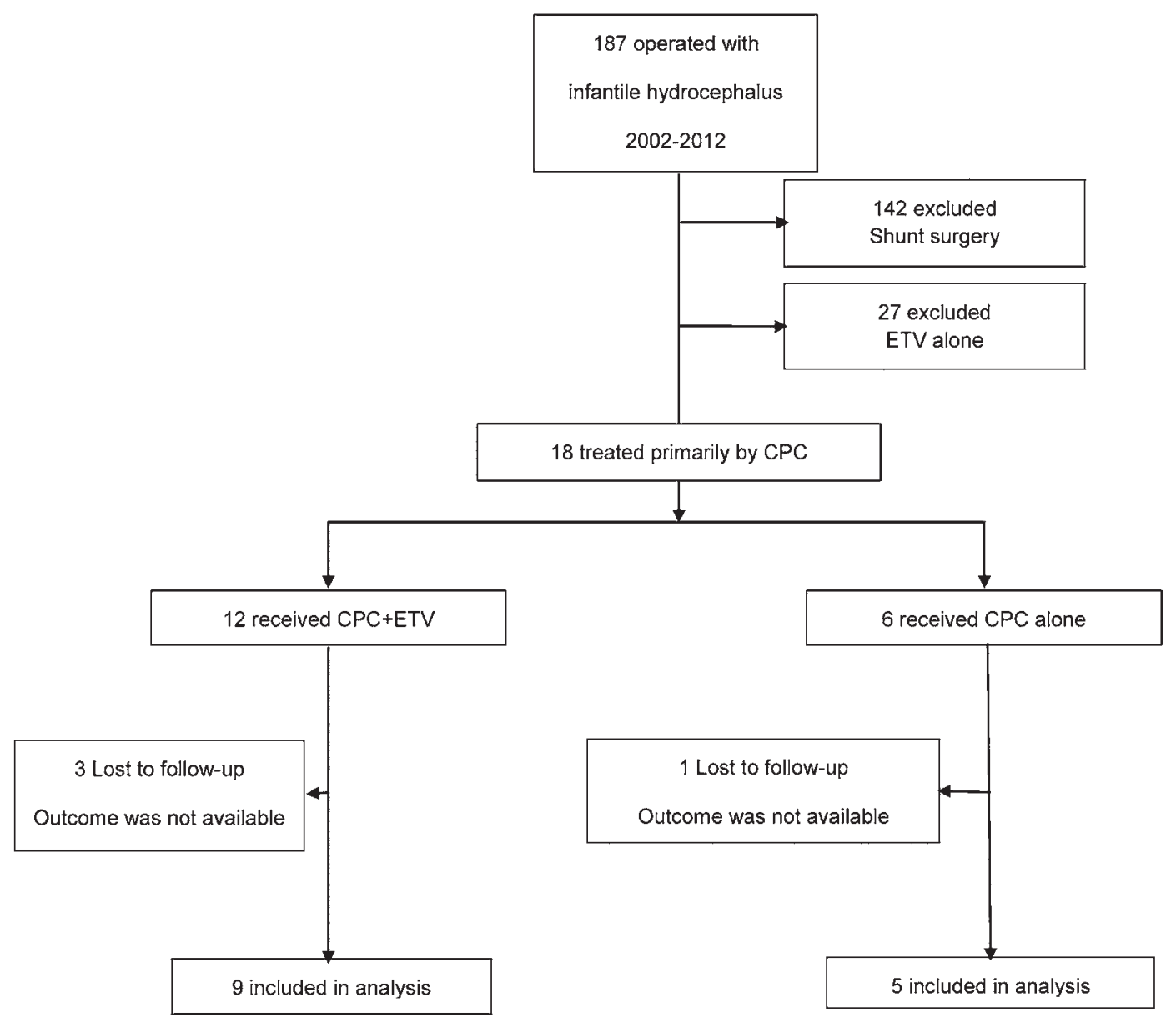

FIG. 1. Enrollment, treatment, follow-up, and analysis. 
selected in cases of communicating hydrocephalus. When parents strongly desired endoscopic procedures as an initial treatment, CPC or a combination of CPC and ETV was selected. Thus, 5 patients with obstructive hydrocephalus and 4 patients with communicating hydrocephalus were treated by a combination of CPC and ETV, and 5 patients with communicating hydrocephalus were treated by CPC alone. Postoperatively, neuroimaging was performed in all patients, and the sizes of the ventricles were assessed at 2 weeks, 6 months, 1 year, and then on a yearly basis after the surgery (Fig. 2). If there were any symptoms that suggested increased intracranial pressure, such as increasing head circumference, vomiting, or headache, a repeat imaging study was performed to assess the size of the ventricles. We judged that it was symptomatic hydrocephalus when there were signs of an increasing head circumference, bulging anterior fontanel with or without CSF leakage, or papilledema, which usually entailed increasing the size of the ventricles compared to their immediate postoperative size. We defined the failure of CPC with or without ETV as the recurrence of symptomatic hydrocephalus requiring an additional CSF diversion surgery. Regarding long-term follow-up, we assessed educational status and full-scale intelligence quotient (FSIQ) by Wechsler Intelligence Scale for Children (WISC) IV as the evaluation tool for establishing intellectual development. WISC IV was not performed for children who were intellectually severely disabled. Several patients were also lost to followup insofar as they moved before performing the WISC IV. The WISC IV was performed in 25 patients primarily treated with VP shunt surgery. In this group, the Kyoto Scale of Psychological Development or Tanaka-Binet Intelligence Test was also performed to evaluate intelligence in 22 patients who had not reached the age appropriate to be evaluated by WISC IV. WISC IV is generally used to assess the intellectual ability of school-aged children. The test is composed of Verbal Comprehension, Perceptional Reasoning, Working Memory, and Processing Speed Indices. The Kyoto Scale of Psychological Development or the Tanaka-Binet Intelligence Test was also applicable to infants and severely handicapped children. Average scores on the FSIQ are 80 to 120 . In our study, this test was administered by skilled language therapists.

Operative methods for CPC with or without ETV were detailed in our previous report. ${ }^{20}$ Briefly, a nondominant frontal approach was selected for patients who underwent concurrent ETV. A nondominant parietal approach was usually chosen for patients who underwent CPC alone. All of the procedures were performed using a flexible endoscope. For a frontal approach, an entry site was made approximately $1 \mathrm{~cm}$ anterior to the coronal suture and slightly lateral to the midpupillary line for coagulation of both the ipsilateral and the contralateral side. For a parietal approach, an entry site was made at the high parietal region and 3-4 cm lateral from the midline, which would be the optimal point for accessing both the foramen of Monro and the temporal horn. In cases of CPC combined with ETV, fenestration of the floor of the third ventricle was performed using closed forceps. The fenestration was dilated using a Fogarty balloon catheter. All visible parts of the bilateral choroid plexus from the foramen of Monro and
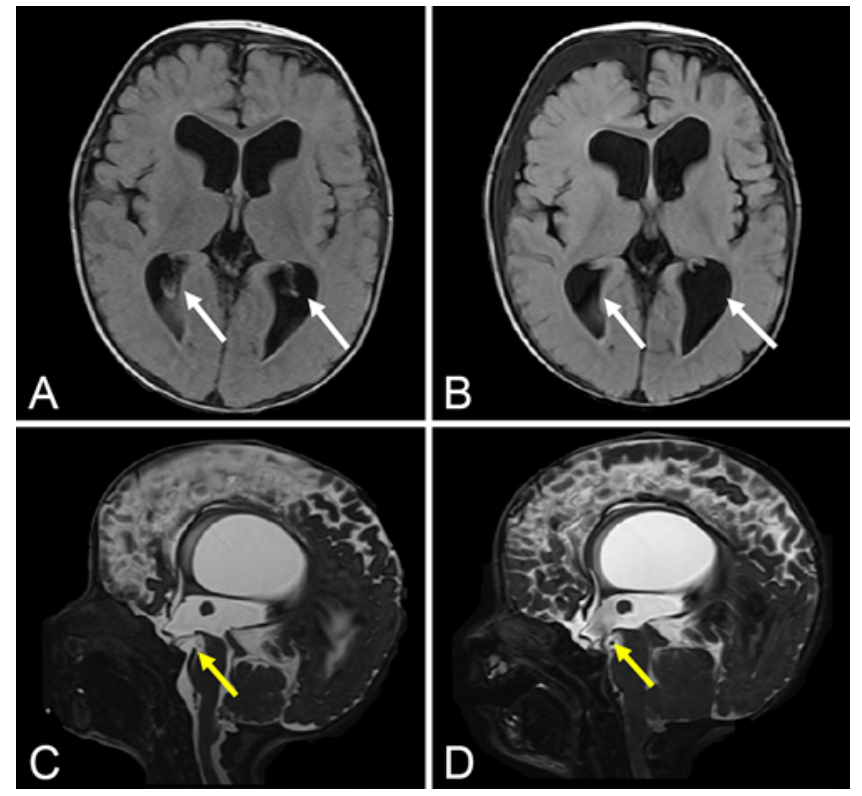

FIG. 2. Preoperative and postoperative MR images. Preoperative (A) and postoperative (B) FLAIR images. Choroid plexus is not visualized after CPC was performed (white arrows). Preoperative (C) and postoperative (D) T2-weighted images. A flow void is present postoperatively after ETV was performed (yellow arrows). Figure is available in color online only.

temporal horn were coagulated using an endoscopic monopolar cautery electrode. When the septum pellucidum was missing, a septostomy was performed in the proximity of the foramen of Monro, and the contralateral choroid plexus was coagulated as well (Fig. 3). In the present study, we chose a high parietal approach in only one case. In this patient, the septum pellucidum was missing, which enabled access to the choroid plexus of the contralateral glomus.

We performed Fisher's exact test to assess nominal variables and independent t-tests for continuous variables in univariate analysis. We also performed multiple logistic regression analysis of the factors that were likely to affect the success of CPC with or without ETV. In addition, Kaplan-Meier time-to-event curves were used to estimate the risk of an event for each group (Fig. 4). Fisher's exact test was applied to determine the difference in the rate of normal intellectual development (Fig. 5), etiology, age distribution, mechanisms of hydrocephalus, and treatment methods between the shunt-independent group and shuntdependent group (Table 1). These analyses were performed using JMP Pro Version 13 (SAS Institute). A value of $\mathrm{p}<$ 0.05 was considered to indicate statistical significance.

\section{Results}

\section{Patient Characteristics}

From 2002 to 2012, 14 patients with infantile hydrocephalus underwent CPC with or without ETV. None of patients had undergone shunt placement before endoscopic surgery. Seven patients were male and 7 were female. The median age at surgery was 7.5 months (range 0-24 months). The etiology of hydrocephalus was posthemorrhagic in 4 patients, idiopathic in $4, \mathrm{MMC}$ in 2 , postmen- 

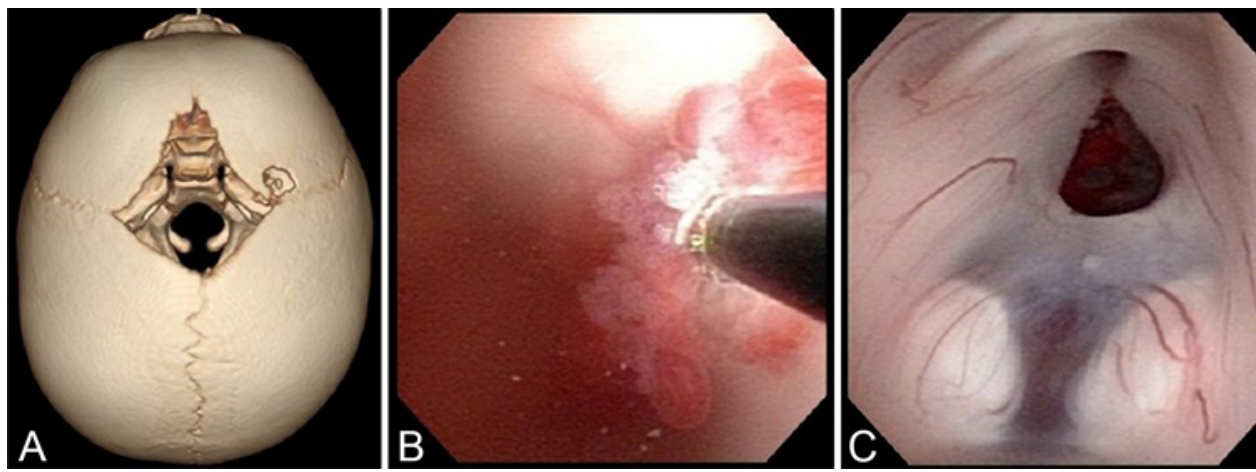

FIG. 3. Intraoperative views of the right anterior horn puncture during endoscopic surgery. A: The position of the burr hole shown on a postoperative CT scan. B: Cauterization of the choroid plexus using an endoscopic monopolar cautery electrode. C: The fenestration of the floor of the third ventricle as viewed by the flexible endoscope. Figure is available in color online only.

ingitis in 2, congenital aqueductal stenosis in 1 , and porencephaly in 1 . Five patients had obstructive mechanisms detected by preoperative MRI. Of these 5 patients, 3 had aqueductal obstruction and 2 had fourth ventricle outlet obstruction (Table 2). The preoperative mean ETV success score (ETVSS) was $49.3 \pm 6.2$ (range 10-80) (Table 3).

\section{Endoscopic Surgery and Complications}

In 9 cases CPC and ETV were concurrently performed. The etiology of hydrocephalus in those patients was idiopathic in 3 patients, MMC in 2, posthemorrhagic in 2, postmeningitis in 1, and congenital aqueductal stenosis in 1 . In the other 5 cases in which CPC alone was performed, the etiology of hydrocephalus was posthemorrhagic in 2 , idiopathic in 2, and postmeningitis in 1. There were no perioperative complications such as intraventricular hemorrhage or damage to significant intracerebral structures or major vessels.

\section{Follow-Up and Treatment Outcome}

The mean follow-up period was 89.0 months (range 56-153 months). In 7 patients $(50 \%, 7 / 14)$, hydrocephalus was successfully controlled by primary surgery, and the patients did not require further CSF diversion. In 6 patients (43\%), VP shunt placement was eventually performed. In 1 patient, hydrocephalus was controlled by additional ETV. The median interval to treatment failure was 3 months (range 2-38 months). The survival curve in Fig. 4 shows the time to treatment failure for patients who underwent CPC with or without ETV. Nine of 14 patients were treated by CPC combined with ETV, and 5 patients were treated by CPC alone. The mean ETVSS of patients who underwent CPC only was $46 \pm 12.9$ and that of the those who underwent combined CPC and ETV was 51.1 \pm 7.0 . There was no statistically significant difference between the ETVSS of patients who underwent CPC only and patients who underwent CPC with ETV $(p=0.71)$. Of the children treated with CPC alone, 4 of 5 patients $(80 \%)$ did not require shunt placement. Of the patients treated with CPC and ETV, 4 of $9(44.4 \%)$ did not require shunt placement. The difference was not statistically significant according to the log-rank test $(\mathrm{p}=0.12)$ (Fig. 4).

We also compared the etiology of hydrocephalus, age at onset, mechanism, and primary treatment of the shuntindependent and shunt-dependent groups (Table 1). There was no statistically significant difference in these characteristics either.

\section{Long-Term Intellectual Outcome}

In the present study, $58 \%$ of the patients $(n=8)$ who underwent CPC as a primary surgery went to age-appropriate school. Six of 8 children were assessed by WISC IV. The average FSIQ score of these patients was $90.3 \pm 3.9$ (range 77-107).

In the shunt-independent group, 4 patients went to ageappropriate school or achieved age-appropriate development, 1 patient went to specialized school, and 2 patients were disabled. In the shunt-dependent group, 4 patients went to age-appropriate school or achieved age-appropriate development, 1 patient went to specialized school, and 1 patient was disabled. There was no significant difference in the rate of normal development between the shunt-independent group and the shunt-dependent group $(p=0.72)$ (Fig. 5A and B). We administered the WISC IV to 7 patients. The mean FSIQ score in 3 patients without a shunt was $90.0 \pm 1.0$ (range 89-91) and the mean FSIQ score in

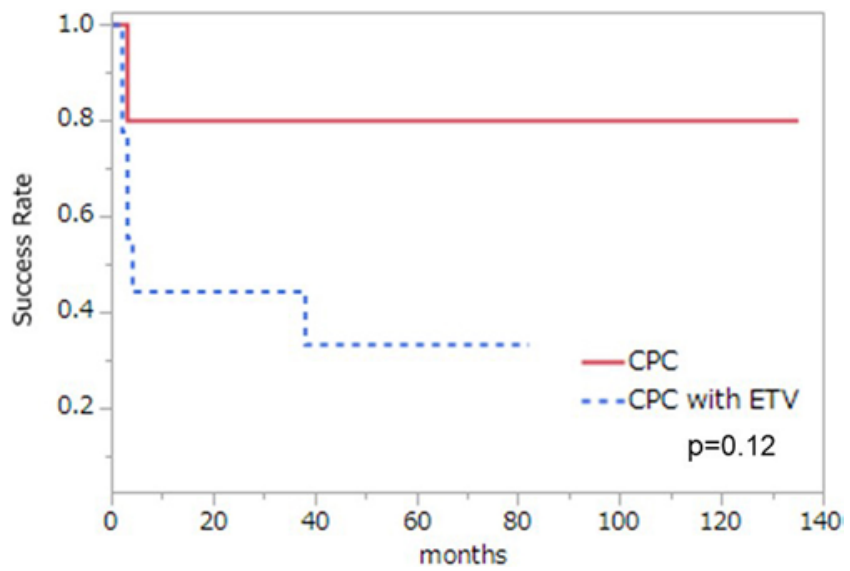

FIG. 4. Kaplan-Meier survival curve comparing the time to failure between CPC only and CPC with ETV. There is no statistically significant difference $(p=0.12)$. Figure is available in color online only. 

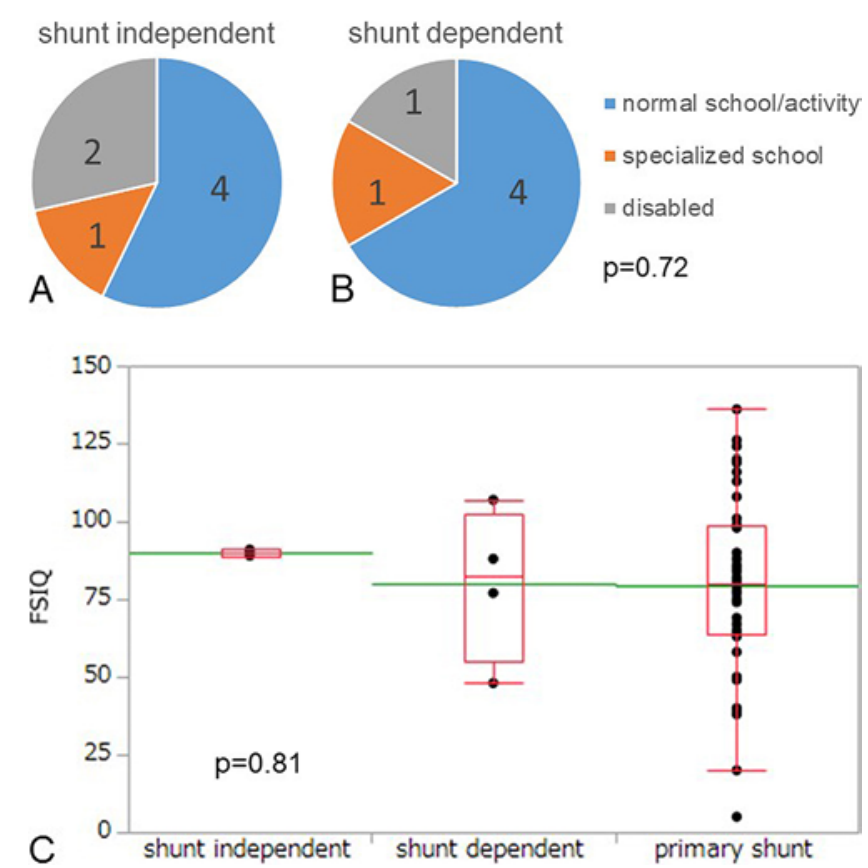

FIG. 5. Pie charts of the number of patients who underwent $C P C$ with or without ETV $(\mathbf{A})$ and VP shunt placement $(\mathbf{B})$. There is no statistically significant difference $(p=0.72)$. Box plot showing comparison of FSIQ scores between the cases of CPC with or without ETV and VP shunt (C). There is no statistically significant difference $(p=0.81)$. Figure is available in color online only.

4 patients with a shunt was $80.0 \pm 24.7$ (range $48-107$ ). We also performed intellectual assessment of patients primarily treated with VP shunt surgery to obtain control data. The mean FSIQ score in these patients was $79.5 \pm 27.9$ (range 5-136). There was no significant difference in the

TABLE 1. Comparison of shunt-independent group and shuntdependent group

\begin{tabular}{lccc}
\hline \multicolumn{1}{c}{ Clinical Data } & $\begin{array}{c}\text { Shunt } \\
\text { Independent }\end{array}$ & $\begin{array}{c}\text { Shunt } \\
\text { Dependent }\end{array}$ & p Value \\
\hline Hydrocephalus etiology & & & \\
\hline Posthemorrhagic & 1 & 3 & \\
\hline MMC & 1 & 1 & \\
\hline Postinfectious & 2 & 0 & \\
\hline Aqueductal stenosis & 0 & 1 & \\
\hline Porencephaly & 1 & 0 & \\
\hline Idiopathic & 2 & 2 & 0.42 \\
\hline Age & & & \\
\hline $0-6$ mos & 2 & 3 & \\
\hline$>6$ mos & 5 & 3 & 0.42 \\
\hline Mechanism & & & \\
\hline Noncommunicating & 2 & 2 & \\
\hline Communicating & 5 & 4 & 0.13 \\
\hline Treatment & & 5 & \\
\hline ETV+CPC & 3 & 1 & \\
\hline CPC & 4 & & \\
\hline
\end{tabular}

TABLE 2. Patients characteristics

\begin{tabular}{|c|c|c|c|c|c|}
\hline $\begin{array}{l}\text { Case } \\
\text { No. }\end{array}$ & $\begin{array}{l}\text { Age } \\
\text { (mos) }\end{array}$ & Sex & Etiology & Symptom & $\begin{array}{c}\mathrm{FU} \\
\text { (mos) }\end{array}$ \\
\hline 1 & 5 & $\mathrm{~F}$ & $\begin{array}{r}\text { Intraventricular } \\
\text { hemorrhage }\end{array}$ & $\begin{array}{l}\text { High intracranial } \\
\text { pressure }\end{array}$ & 153 \\
\hline 2 & 12 & M & Aqueductal stenosis & Seizure & 84 \\
\hline 3 & 7 & $\mathrm{~F}$ & MMC & Bulging fontanelle & 132 \\
\hline 4 & 2 & M & $\begin{array}{r}\text { Intraventricular } \\
\text { hemorrhage }\end{array}$ & Increasing HC & 15 \\
\hline 5 & 0.3 & M & $\begin{array}{r}\text { Intraventricular } \\
\text { hemorrhage }\end{array}$ & Increasing $\mathrm{HC}$ & 56 \\
\hline 6 & 24 & $\mathrm{~F}$ & Idiopathic & $\begin{array}{l}\text { Increasing } \mathrm{HC} \text {, } \\
\text { headache }\end{array}$ & 92 \\
\hline 7 & 3 & $\mathrm{~F}$ & Meningitis & Increasing HC & 82 \\
\hline 8 & 7 & M & Idiopathic & Increasing $\mathrm{HC}$ & 84 \\
\hline 9 & 9 & M & Idiopathic & Increasing $\mathrm{HC}$ & 82 \\
\hline 10 & 8 & $\mathrm{~F}$ & Idiopathic & $\begin{array}{l}\text { Increasing } \mathrm{HC} \text {, bulg- } \\
\text { ing fontanelle }\end{array}$ & 84 \\
\hline 11 & 12 & M & Meningitis & Increasing HC & 83 \\
\hline 12 & 12 & $\mathrm{~F}$ & Idiopathic & Increasing $\mathrm{HC}$ & 60 \\
\hline 13 & 1 & $\mathrm{~F}$ & $\begin{array}{r}\text { Intraventricular } \\
\text { hemorrhage }\end{array}$ & Increasing $\mathrm{HC}$ & 59 \\
\hline 14 & 11 & $M$ & MMC & Increasing $\mathrm{HC}$ & 60 \\
\hline
\end{tabular}

$\mathrm{FU}=$ follow-up; $\mathrm{HC}=$ head circumference.

mean FSIQ score among patients in the shunt-independent group, the shunt-dependent group, and the group primarily treated by shunts $(\mathrm{p}=0.81)$ (Fig. $5 \mathrm{C})$.

\section{Discussion}

Standard treatment for infantile hydrocephalus has been shunt surgery. Recently, due to advancements in neuroendoscopy, the use of CPC with or without ETV as a primary treatment has been reported. ${ }^{3,9-11,13,17,19,25,27,30}$ In the reports from Sub-Saharan Africa, ETV combined with CPC was effective in avoiding the need for shunt surgery, but its effects on long-term cognitive function were not discussed. ${ }^{1,31}$ In North America, favorable short-term results of ETV and CPC have been reported. ${ }^{15,29}$ However, these reports also did not demonstrate long-term outcome, including patients' intellectual development, of CPC with or without ETV.

\section{Long-Term Outcome of CPC Compared to VP Shunt}

Previous studies have reported that there were some cases of infantile hydrocephalus for which CPC with or without ETV was an appropriate therapy. ${ }^{5,15,19,29,31}$ However, these studies did not state whether or not CPC itself affected long-term intellectual development of the treated patients. The purpose of our study was to assess long-term outcome, including intellectual development and educational status after CPC. In 2015, Paulsen et al. reported that they performed VP shunt placement in 128 patients with childhood hydrocephalus, and $67 \%$ went to regular school, $20 \%$ had physical disabilities, and 13\% had intel- 
TABLE 3. Operative and postoperative results

\begin{tabular}{cllccccccc}
\hline Case No. & Aqueductal Stenosis & ETV & Complications & ETVSS & Failure & VPS & \multicolumn{2}{c}{ Outcome } & FSIQ Score \\
\hline 1 & No & Yes & No & 30 & Yes & Yes & Specialized school & 48 \\
\hline 2 & Yes & Yes & No & 70 & Yes & No & Specialized school & NA \\
\hline 3 & Yes & Yes & No & 40 & Yes & Yes & Standard school & 77 \\
\hline 4 & No & No & No & 30 & No & No & Care needed & NA \\
\hline 5 & No & No & No & 10 & Yes & Yes & Care needed & NA \\
\hline 6 & No & No & No & 80 & No & No & Standard school & 91 \\
\hline 7 & Yes & Yes & No & 20 & No & No & Standard school & 89 \\
\hline 8 & No & No & No & 70 & No & No & Care needed & NA \\
\hline 9 & No & Yes & No & 70 & Yes & Yes & Standard school & 107 \\
\hline 10 & 4 th ventricle outlet & Yes & No & 70 & Yes & Yes & Standard school & 88 \\
\hline 11 & No & No & No & 40 & No & No & Standard school & NA \\
\hline 12 & No & Yes & No & 70 & No & No & Specialized school & NA \\
\hline 13 & No & Yes & No & 30 & Yes & Yes & Standard activity & NA \\
\hline 14 & 4th ventricle outlet & Yes & No & 60 & No & No & Standard activity & 90 \\
\hline
\end{tabular}

NA $=$ not applicable; VPS $=$ VP shunt.

lectual disabilities. Much of the intellectual disability is caused by postmeningitis, tumor, and posthemorrhagic hydrocephalus. These patients with physical or intellectual disabilities went to specialized school. Most of the patients who went to typical schools needed additional support in their life. ${ }^{22}$ In our study, 58\% (8/14) of the patients who underwent CPC as a primary surgery went to typical school. Six of 8 patients who went to typical schools were assessed by the WISC IV. The average FSIQ score of these patients was $90.3 \pm 3.9$ (range 77-107). These results show that there was no significant difference in educational status between patients who underwent CPC with or without ETV as a primary surgery in our study and the patients who underwent VP shunt placement as a primary surgery in the previous study $(\mathrm{p}=0.48)$. Also, in our study, there was no significant difference in the mean FSIQ score among patients in the shunt-independent group, the shunt-dependent group, and the group treated primarily by shunts (Fig. 5). Although we should interpret this result carefully because of the heterogeneity in etiology and the severity of hydrocephalus, the long-term intellectual outcome of patients treated with CPC in our study was considered to be acceptable.

\section{Technical Point of CPC}

The degree of CPC might be associated with the success of ETV combined with CPC..$^{15}$ The procedure was more successful in those in whom more than 90\% CPC was achieved. In all cases except one, more than $90 \%$ CPC was achieved in our study. We find that a flexible endoscope is effective for more extensive coagulation. Coagulation of the choroid plexus using endoscopic monopolar probe is straightforward, but a skilled technique is required in order not to damage the thalamus and the major vein including thalamostriate vein and septal vein. The power of the monopolar probe should be appropriately adjusted, and a safe distance should be maintained between the monopolar probe and the major vein and brain tissue.
We prepared an operative microscope for emergency use to stop significant accidental bleeding from the choroid plexus, although we have not had to use it so far. Regarding short-term mortality and morbidity associated with the surgery, no complications occurred in our study.

\section{Surgical Indication and Etiology}

The surgical indication for CPC with or without ETV remains controversial. We usually chose ETV alone for obstructive hydrocephalus with aqueductal stenosis or fourth ventricular outlet obstruction. Occasionally, for young infants with obstructive hydrocephalus, we performed CPC in addition to ETV. A VP shunt was usually inserted for communicating hydrocephalus. CPC or CPC with ETV was selected when parents strongly desired endoscopic surgery as the first treatment in patients with communicating hydrocephalus.

CPC alone can control hydrocephalus for some patients. Morota and Fujiyama stressed that the most important factor for CPC success is patient selection, and favorable candidates are those with severely advanced hydrocephalus, slowly progressive hydrocephalus, and easy access to bilateral ventricles for the endoscope, which enables extensive coagulation..$^{19}$ Pedrosa et al. and Malheiros et al. also reported that CPC was an acceptable alternative to VP shunt surgery for hydranencephaly. ${ }^{18,23}$ On the other hand, combined ETV and CPC has been performed as an alternative surgery to VP shunt and its effectiveness has been reported. . $^{3,9-11,13,17,19,25,27,30}$ Previous studies reported that the factors affecting the success of combined ETV and CPC included the etiology of hydrocephalus, age at surgery, crowded prepontine cistern shown on MRI, prior CSF di-

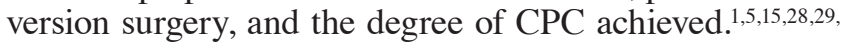
${ }^{31-33}$ Regarding the etiology of hydrocephalus, combined ETV and CPC was reported to be effective for hydrocephalus associated with MMC, Dandy-Walker complex, and congenital aqueductal stenosis, with success rates of $76 \%$, $74 \%$, and $81.9 \%$, respectively. ${ }^{34}$ For posthemorrhagic hy- 
drocephalus, combined ETV and CPC was effective especially when an unscarred prepontine cistern was present..$^{33}$ The efficacy of combined ETV and CPC compared to that of ETV has not been proven for postinfectious hydrocephalus. ${ }^{29,31,33}$ Bankole et al. also reported that combined ETV and $\mathrm{CPC}$ was useful in treating children with hydrocephalus of varied etiologies, except for postinfectious hydrocephalus. ${ }^{1}$ Chamiraju et al. identified two related factors to the failure of the procedure: a patient's corrected gestational age of $<0$ weeks at surgery and an MRI-documented narrow prepontine cistern. ${ }^{5}$ Warf reported that combined ETV and CPC was successful in older patients, with a $66 \%$ success rate in those $<1$ year of age and an $80 \%$ success rate in those $>1$ year of age.$^{31}$ Stone and Warf reported that an age at treatment $<6$ months, prepontine cistern scarring, and prior CSF diversion procedure were independent predictors of ETV and CPC failure. ${ }^{29}$

In our study, the etiology of hydrocephalus, onset age, mechanism, and primary surgery (CPC with or without ETV) did not relate to the success rate of CPC. Further prospective studies should be required to elucidate which patients are best indicated for CPC alone, combined CPC and ETV, or VP shunt surgery.

\section{Function of Choroid Plexus and Cause of Hydrocephalus}

The mechanism of hydrocephalus has not yet been fully elucidated, and several theories have been debated. ${ }^{21}$ The traditional bulk flow model is based on production of the CSF by the choroid plexus. On the other hand, the hydrodynamic model assumes that a choroid plexus-related increase in intraventricular pulsation amplitude is the cause of progressive ventriculomegaly in communicating hydrocephalus. The presence of the choroid plexus has also been reported as being necessary to produce ventriculomegaly. ${ }^{2,8,35}$ Other studies have shown that in a communicating hydrocephalus model, the ventricles have failed to expand in the absence of normal choroid plexus pulsations. ${ }^{6,24}$ These studies might be the theoretical basis for CPC for the treatment of hydrocephalus. However, its long-term efficacy has not been well reported. Previously, we demonstrated that obliteration of the choroid plexus can persist in the relatively long term following CPC. ${ }^{20}$ In the present study, we showed that long-term control of hydrocephalus and typical intellectual development can be achieved in successful cases.

\section{Limitations}

There were some limitations in this study. First, this was a retrospective study and lacked a control group. Second, direct comparisons of CPC with other treatment options were not performed. Third, the series population is too small and too heterogeneous to evaluate outcome. We could not evaluate intellectual development in all cases. These limitations should be carefully considered when interpreting the results. To confirm our results, a prospective randomized clinical trial in a large number of patients with hydrocephalus and a variety of treatments, such as shunt surgery and ETV alone, would be required.

\section{Conclusions}

CPC with or without ETV can be a safe and effective treatment in infantile hydrocephalus. Long-term control of hydrocephalus and typical intellectual development can be achieved in successful cases. Further prospective study should be required to elucidate appropriate indications.

\section{References}

1. Bankole OB, Ojo OA, Nnadi MN, Kanu OO, Olatosi JO: Early outcome of combined endoscopic third ventriculostomy and choroid plexus cauterization in childhood hydrocephalus. J Neurosurg Pediatr 15:524-528, 2015

2. Bering EA Jr: Circulation of the cerebrospinal fluid. Demonstration of the choroid plexuses as the generator of the force for flow of fluid and ventricular enlargement. J Neurosurg 19:405-413, 1962

3. Bucholz RD, Pittman T: Endoscopic coagulation of the choroid plexus using the Nd:YAG laser: initial experience and proposal for management. Neurosurgery 28:421-427, 1991

4. Buxton N, Macarthur D, Mallucci C, Punt J, Vloeberghs M: Neuroendoscopic third ventriculostomy in patients less than 1 year old. Pediatr Neurosurg 29:73-76, 1998

5. Chamiraju P, Bhatia S, Sandberg DI, Ragheb J: Endoscopic third ventriculostomy and choroid plexus cauterization in posthemorrhagic hydrocephalus of prematurity. J Neurosurg Pediatr 13:433-439, 2014

6. Di Rocco C, Pettorossi VE, Caldarelli M, Mancinelli R, Velardi F: Communicating hydrocephalus induced by mechanically increased amplitude of the intraventricular cerebrospinal fluid pressure: experimental studies. Exp Neurol 59:40-52, 1978

7. Drake JM: Endoscopic third ventriculostomy in pediatric patients: the Canadian experience. Neurosurgery 60:881-886, 2007

8. Egnor M, Zheng L, Rosiello A, Gutman F, Davis R: A model of pulsations in communicating hydrocephalus. Pediatr Neurosurg 36:281-303, 2002

9. Hallaert GG, Vanhauwaert DJ, Logghe K, Van den Broecke C, Baert E, Van Roost D, et al: Endoscopic coagulation of choroid plexus hyperplasia. J Neurosurg Pediatr 9:169-177, 2012

10. Idowu OE, Falope LO, Idowu AT: Outcome of endoscopic third ventriculostomy and Chhabra shunt system in noncommunicating non-tumor childhood hydrocephalus. J Pediatr Neurosci 4:66-69, 2009

11. Jones RF, Stening WA, Brydon M: Endoscopic third ventriculostomy. Neurosurgery 26:86-92, 1990

12. Kadrian D, van Gelder J, Florida D, Jones R, Vonau M, Teo $\mathrm{C}$, et al: Long-term reliability of endoscopic third ventriculostomy. Neurosurgery 62 (Suppl 2):614-621, 2008

13. Koch D, Wagner W: Endoscopic third ventriculostomy in infants of less than 1 year of age: which factors influence the outcome? Childs Nerv Syst 20:405-411, 2004

14. Kulkarni AV, Drake JM, Mallucci CL, Sgouros S, Roth J, Constantini S: Endoscopic third ventriculostomy in the treatment of childhood hydrocephalus. J Pediatr 155:254-259, 259.e1, 2009

15. Kulkarni AV, Riva-Cambrin J, Browd SR, Drake JM, Holubkov R, Kestle JR, et al: Endoscopic third ventriculostomy and choroid plexus cauterization in infants with hydrocephalus: a retrospective Hydrocephalus Clinical Research Network study. J Neurosurg Pediatr 14:224-229, 2014

16. Kulkarni AV, Schiff SJ, Mbabazi-Kabachelor E, Mugamba J, Ssenyonga P, Donnelly R, et al: Endoscopic treatment versus shunting for infant hydrocephalus in Uganda. N Engl J Med 377:2456-2464, 2017

17. Lee SH, Kong DS, Seol HJ, Shin HJ: Endoscopic third ventriculostomy in patients with shunt malfunction. J Korean Neurosurg Soc 49:217-221, 2011

18. Malheiros JA, Trivelato FP, Oliveira MM, Gusmão S, Co- 
chrane DD, Steinbok P: Endoscopic choroid plexus cauterization versus ventriculoperitoneal shunt for hydranencephaly and near hydranencephaly: a prospective study. Neurosurgery 66:459-464, 2010

19. Morota N, Fujiyama Y: Endoscopic coagulation of choroid plexus as treatment for hydrocephalus: indication and surgical technique. Childs Nerv Syst 20:816-820, 2004

20. Ogiwara H, Uematsu K, Morota N: Obliteration of the choroid plexus after endoscopic coagulation. J Neurosurg Pediatr 14:230-233, 2014

21. Orešković D, Radoš M, Klarica M: Role of choroid plexus in cerebrospinal fluid hydrodynamics. Neuroscience 354:6987, 2017

22. Paulsen AH, Lundar T, Lindegaard KF: Pediatric hydrocephalus: 40-year outcomes in 128 hydrocephalic patients treated with shunts during childhood. Assessment of surgical outcome, work participation, and health-related quality of life. J Neurosurg Pediatr 16:633-641, 2015

23. Pedrosa HAR, Lemos SP, Vieira C, Amaral LC, Malheiros JA, Oliveira MM, et al: Choroid plexus cauterization on treatment of hydranencephaly and maximal hydrocephalus. Childs Nerv Syst 33:1509-1516, 2017

24. Pettorossi VE, Di Rocco C, Mancinelli R, Caldarelli M, Velardi F: Communicating hydrocephalus induced by mechanically increased amplitude of the intraventricular cerebrospinal fluid pulse pressure: rationale and method. Exp Neurol 59:30-39, 1978

25. Pople IK, Ettles D: The role of endoscopic choroid plexus coagulation in the management of hydrocephalus. Neurosurgery 36:698-702, 1995

26. Scarff JE: Nonobstructive hydrocephalus. Treatment by endoscopic cauterization of the choroid plexus. Long term results. J Neurosurg 9:164-176, 1952

27. Scarff JE: The treatment of nonobstructive (communicating) hydrocephalus by endoscopic cauterization of the choroid plexuses. J Neurosurg 33:1-18, 1970

28. Shimony N, Ben-Sira L, Sivan Y, Constantini S, Roth J: Surgical treatment for cervicomedullary compression among infants with achondroplasia. Childs Nerv Syst 31:743-750, 2015

29. Stone SS, Warf BC: Combined endoscopic third ventriculostomy and choroid plexus cauterization as primary treatment for infant hydrocephalus: a prospective North American series. J Neurosurg Pediatr 14:439-446, 2014

30. Teo C, Jones R: Management of hydrocephalus by endoscop- ic third ventriculostomy in patients with myelomeningocele. Pediatr Neurosurg 25:57-63, 1996

31. Warf BC: Comparison of endoscopic third ventriculostomy alone and combined with choroid plexus cauterization in infants younger than 1 year of age: a prospective study in 550 African children. J Neurosurg 103 (6 Suppl):475-481, 2005

32. Warf BC, Campbell JW: Combined endoscopic third ventriculostomy and choroid plexus cauterization as primary treatment of hydrocephalus for infants with myelomeningocele: long-term results of a prospective intent-to-treat study in 115 East African infants. J Neurosurg Pediatr 2:310-316, 2008

33. Warf BC, Campbell JW, Riddle E: Initial experience with combined endoscopic third ventriculostomy and choroid plexus cauterization for post-hemorrhagic hydrocephalus of prematurity: the importance of prepontine cistern status and the predictive value of FIESTA MRI imaging. Childs Nerv Syst 27:1063-1071, 2011

34. Warf BC, Tracy S, Mugamba J: Long-term outcome for endoscopic third ventriculostomy alone or in combination with choroid plexus cauterization for congenital aqueductal stenosis in African infants. J Neurosurg Pediatr 10:108-111, 2012

35. Wilson $\mathrm{CB}$, Bertan V: Interruption of the anterior choroidal artery in experimental hydrocephalus. Arch Neurol 17:614619,1967

\section{Disclosures}

The authors report no conflict of interest concerning the materials or methods used in this study or the findings specified in this paper.

\section{Author Contributions}

Conception and design: both authors. Acquisition of data: Okano. Analysis and interpretation of data: both authors. Drafting the article: Okano. Critically revising the article: Ogiwara. Reviewed submitted version of manuscript: Ogiwara. Approved the final version of the manuscript on behalf of both authors: Ogiwara. Statistical analysis: Okano.

\section{Correspondence}

Hideki Ogiwara: National Center for Child Health and Development, Tokyo, Japan. hideki_o@d5.dion.ne.jp. 